\title{
Desempenho Produtivo de Cabritos Alimentados com Diferentes Dietas Líquidas, Associadas com Promotor de Crescimento ${ }^{1}$
}

\author{
Antonio Bento Mancio², Rafael Henrique de Tonissi e Buschinelli de Goes ${ }^{3}$, Emanoel Elzo Leal \\ de Barros ${ }^{4}$, Eliane Menin ${ }^{2}$, Paulo Roberto Cecon $^{5}$, Alonso Thiago Silvestre da Silva ${ }^{6}$
}

\begin{abstract}
RESUMO - O experimento foi conduzido para se avaliar o desempenho de cabritos tratados com leite de cabra integral ou colostro de vaca fermentado com ou sem óleo de soja, e com aplicação ou não do promotor de crescimento Zeranol. Vinte e quatro cabritos da raça Alpina foram dispostos em delineamento inteiramente casualizado em esquema fatorial $3 \times 2$. Cada animal recebeu, pela manhã, $1 \mathrm{~L}$ da dieta líquida e $250 \mathrm{~g} / \mathrm{animal} /$ dia de concentrado. Foram avaliados o ganho de peso dos animais, os consumos de concentrado e de matéria seca, a conversão alimentar e o tamanho dos órgãos. Houve diferenças entre as dietas líquidas, com ou sem a aplicação de Zeranol, para ganho de peso aos 29, 36, e 50 dias de idade, mas não para o ganho médio diário. A não aplicação de Zeranol nos tratamentos com leite de cabra e colostro fermentado com óleo de soja proporcionou diferença média de $8 \%$ no ganho de peso dos animais alimentados com leite de cabra. Não se observou diferença nos consumos de concentrado e de matéria seca e na conversão alimentar dos animais entre as diferentes dietas líquidas avaliadas. Não houve influência do Zeranol ou do óleo de soja nas dietas líquidas sobre nenhum dos órgãos estudados.
\end{abstract}

Palavras-chave: caprinos, biometria, colostro fermentado, óleo de soja, rúmen-retículo, Zeranol

\section{Effects of Feeding Different Liquid Diets with or without Growth Promoter on Performance of Kid Goats}

\begin{abstract}
The objective of this experiment was to study the effects of feeding whole goat milk or fermented cow colostrum supplemented or not with soy oil and with or without the growth promoter Zeranol on performance of kid goats. Twenty-four Alpine kid goats assigned to a completely randomized design in a 3 x 2 factorial arrangement were used in this trial. The following variables were investigated: weight gain, intakes of dry matter and concentrate, feed conversion, and organ sizes. Significant differences were observed among liquid diets with or without Zeranol for weight gain at 29, 36, and 50 days old, but not for the average daily gain. No significant differences for intake of both dry matter and concentrate as well as for feed conversion were detected among liquid diets. Supplementation of the liquid diets with soy oil and injection of Zeranol did not change the organ sizes.
\end{abstract}

Key Words: goats, development, fermented colostrum, rumen-reticulum, soy oil, Zeranol

\section{Introdução}

A substituição do leite de cabra por leite de vaca ou por outro alimento na fase de crescimento do préruminante é uma prática utilizada visando a redução do custo de produção, possibilitando o aumento de lucro e a queda do preço do produto. O colostro, primeira secreção da glândula mamária logo após o parto, não tem valor comercial e sua produção supera a necessidade do recém-nascido.

Os sucedâneos são produtos sintéticos compostos essencialmente por leite bovino e pela adição de fontes energéticas (sucedâneos de lipídeos, soro de leite em pó e produtos amiláceos), incluindo-se ou não proteínas (Toullec et al., 1980).

No Brasil, vários sucedâneos para o leite caprino foram testados, porém as alternativas à substituição ao leite integral são poucas. A utilização de colostro resfriado ou congelado tem proporcionado resultados satisfatórios para bovinos leiteiros, podendo-se observar ganho de peso igual ou até mesmo superior ao obtido com fornecimento de leite comum (Modesto et al., 2002).

Em razão de o colostro se deteriorar facilmente, o fornecimento após um período de conservação pode-

\footnotetext{
1 Projeto financiado pela FAPEMIG.

2 Professor Adjunto do Departamento de Zootecnia-UFV - Viçosa-MG - 36571-000 (amancio@ufv.br)

${ }^{3}$ Zootecnista, DS, Professor do curso de Medicina Veterinária - DZO/UEM. Campus Regional de Umuarama - PR, 87507-190. (rgoes@elitnet.com.br)

4 Zootecnista, MS, Departamento de Zootecnia - UENF - Campo dos Goytacases-RJ.

${ }^{5}$ Professor do Departamento de Informática-UFV, bolsista do CNPq - Viçosa-MG - 36571-000

${ }^{6}$ Estudante de Agronomia - UFV.
} 
ria maximizar o seu uso e minimizar as perdas. $\mathrm{O}$ processo de fermentação natural foi desenvolvido como forma econômica para o armazenamento desse produto, que pode ser utilizado como substituto ao leite (Lucci, 1989). Morand-Fehr et al. (1982) comentam que, apesar das poucas informações existentes na literatura, os cabritos se adaptam facilmente a sucedâneos do leite das mais variadas composições.

Um dos problemas de aceitabilidade do colostro seria o baixo $\mathrm{pH}$, decorrente da fermentação durante longos períodos e sob altas temperaturas (Rindsing \& Bodoh, 1977), o que pode ser solucionado com a adição de bicarbonato de sódio (Lucci, 1989).

Vários trabalhos são realizados com a finalidade de valorizar o aproveitamento do colostro, por diferentes processos de armazenamento (a frio, seja pela fermentação à temperatura ambiente ou com o uso de produtos químicos). Os processos mais fáceis e de menores custos são as fermentações, simples ou com o uso de aditivos e conservantes.

$\mathrm{O}$ uso de promotores de crescimento tem como objetivo melhorar a eficiência dos processos metabólicos para a deposição de proteína (Gimeno, 1996). Entre os produtos utilizados, destaca-se o Zeranol, um anabolizante sintetizado a partir da zeralenona - um composto estrogênico extraído do fungo de milho Giberrella zeae que proporciona maior porcentagem de proteína e diminuição dos teores de gordura da carcaça.

Hutcheson et al. (1992) observaram que cordeiros tratados com Zeranol apresentaram $26 \%$ a mais em ganho de peso diário e melhoria de $12 \%$ na eficiência alimentar e no consumo. Bachman et al.(1993 a,b) e Modesto et al. (2002) também notaram que a atividade metabólica desses cordeiros não foi afetada pela suplementação com dieta contendo $8 \%$ de proteína bruta, mas os animais apresentaram melhor composição de carcaça.

Neste trabalho, objetivou-se avaliar o desempenho de cabritos recebendo leite de cabra integral ou colostro de vaca fermentado, com ou sem óleo de soja, com aplicação ou não do promotor de crescimento Zeranol.

\section{Material e Métodos}

O experimento foi conduzido no setor de Caprinocultura do Departamento de Zootecnia da Universidade Federal de Viçosa, durante os meses de agosto a dezembro de 1997. Foram utilizados 24 cabritos machos inteiros da raça Alpina, recebendo três diferentes dietas líquidas (leite de cabra integral, colostro de vaca fermentado, e colostro de vaca fermentado + óleo de soja) e a aplicação ou não de Zeranol.

Os animais foram separados das mães logo após o nascimento, identificados e alojados em baias individuais. Cada animal recebeu colostro pasteurizado em baldes com capacidade de um litro. A partir do décimo quinto dia de idade, iniciou-se o período experimental, com o fornecimento da dieta líquida (1 L/animal/dia) pela manhã.

Os animais que receberam o colostro de vaca fermentado passaram por um processo de adaptação durante os 15 primeiros dias de idade, em que receberam pequena quantidade de colostro fermentado misturado ao leite de cabra integral. Após o 15ํaa, estes animais entraram no período experimental, que se estendeu até o $60^{0}$ dia de idade.

O colostro foi acondicionado em galões plásticos de 80 litros de capacidade, mantidos à sombra e homogeneizados diariamente. A fermentação ocorreu ao natural, durante sete dias e o colostro foi utilizado em até 28 dias. Ao colostro de vaca fermentado foram adicionados $10 \mathrm{mg}$ de bicarbonato de sódio, diluídos na proporção de 2:1 $(700 \mathrm{~mL}$ de colostro para $300 \mathrm{~mL}$ de água), quantidade suficiente para atender os requerimentos de energia e proteína propostos pelo NRC (1981) para ganho de peso de cabritos em crescimento. O óleo de soja foi adicionado na quantidade de $10 \mathrm{~mL} /$ litro de colostro, juntamente à lecitina de soja como agente emulsificante, para melhor homogeneização do óleo ao alimento líquido.

O implante do pélete com Zeranol (36 mg) foi feito nos animais dos tratamentos LZ, CFZ e CFOZ, segundo recomendações de Modesto et al. (2002), via subcutânea, na orelha dos animais, ao completarem 15 dias de idade.

A ração concentrada foi fornecida diariamente na proporção de $50 \mathrm{~g} / \mathrm{animal} / \mathrm{dia}$, aumentando-se gradativamente até o limite de $250 \mathrm{~g} / \mathrm{animal} / \mathrm{dia}$ e mensurando-se o concentrado diariamente.

Os teores de matéria seca (MS), proteína bruta $(\mathrm{PB})$, cinzas $(\mathrm{CZ})$, extrato etéreo $(\mathrm{EE})$, fibra em detergente neutro (FDN) e de fibra em detergente ácido (FDA), para as dietas líquidas e sólidas, foram determinados segundo metodologia descrita por Silva \& Queiroz (2002). O teor de carboidratos totais $(\mathrm{CHOT})$ foi estimado por CHOT $(\%)=100-\mathrm{PB} \%$ EE\% - MM\% e os carboidratos não-estruturais, por $\mathrm{CNE}=\mathrm{CHOT}-\mathrm{FDN}$ (Sniffen et al., 1992). Consta, 
nas Tabelas 1 e 2, a composição das diferentes dietas líquidas e dos alimentos sólidos utilizados.

Os órgãos avaliados neste estudo foram rúmenretículo, omaso e abomaso e intestinos delgado e grosso. Os animais foram abatidos aos 60 dias de idade, por secção da veia jugular (para coleta total de sangue) e decapitação. Foram realizadas ligaduras duplas proximais ao esôfago e distal ao reto, antes da retirada do tubo digestivo da região cervical e das cavidades torácica e abdominal.

Os órgãos do tubo digestivo foram isolados, por meio de secção transversal de sua parede, e pesados individualmente. Em seguida, foram devidamente esvaziados e novamente pesados. Para a determinação do peso de corpo vazio (PCVZ), foram pesados o sangue, o aparelho digestivo cheio e vazio, as demais vísceras, a cabeça, as patas, o couro e a carcaça, do total foi deduzida a digesta.

O delineamento estatístico adotado foi o inteiramente casualizado com esquema fatorial $3 \times 2$, e analisado conforme o modelo:

Tabela 1 - Teores de matéria seca (MS), proteína bruta $(P B)$, extrato etéreo (EE) e cinzas (CZ) com base na matéria seca, para as diferentes dietas líquidas

Table 1 - Dry matter (DM), crude protein (CP), ether extract (EE) and ash for different liquids diets, DM basis

\begin{tabular}{lcccc}
\hline Dieta líquida & MS (\%) & PB* (\%) & EE (\%) & CZ (\%) \\
Liquid diet & $D M(\%)$ & $C P(\%)$ & $E E(\%)$ & Ash (\%) \\
\hline $\begin{array}{l}\text { Leite (L) } \\
\text { Milk (M) }\end{array}$ & 9,20 & 33,64 & 3,90 & 6,44 \\
$\begin{array}{l}\text { Colostro fermentado(CF) } \\
\text { Fermented colostrum (FC) }\end{array}$ & 12,77 & 51,21 & 3,40 & 13,24 \\
$\begin{array}{l}\text { CF com óleo (CFO) } \\
\text { FC with oil }\end{array}$ & 10,59 & 43,52 & 5,10 & 11,45 \\
& & & & \\
\hline
\end{tabular}

$$
\begin{gathered}
\mathrm{Y}_{\mathrm{ijkl}}=\mu+\mathrm{A}_{\mathrm{i}}+\underset{\mathrm{j}}{\mathrm{O}_{\mathrm{j}}+\mathrm{P}_{\mathrm{k}}+\mathrm{AO}_{\mathrm{ijk}}+\mathrm{e}_{(\mathrm{ijk})}}+\mathrm{AP}_{\mathrm{ik}}+\mathrm{OP}_{\mathrm{jk}}+ \\
\mathrm{AOP}+
\end{gathered}
$$

em que: $\mu=$ constante geral; $A_{i}=$ efeito referente ao alimento líquido $i(i=1,2$ e 3$) ; \mathrm{O}_{\mathrm{j}}=$ efeito referente à adição de óleo de soja $(\mathrm{j}=1$ e 2$) ; \mathrm{P}_{\mathrm{k}}=$ efeito referente à aplicação do promotor de crescimento $(\mathrm{k}=1$ e 2); $\mathrm{AO}_{\mathrm{ij}}, \mathrm{AP}_{\mathrm{ik}}, \mathrm{OP}_{\mathrm{jk},}, \mathrm{AOP}_{\mathrm{ijk}}=$ interações entre os efeitos principais; e e ${ }_{(\mathrm{ijk})}=$ erro-padrão, associado a cada observação, pressuposto NID $\sim\left(0, \sigma^{2}\right)$.

Os dados foram analisados por intermédio do programa estatístico SAEG (UFV, 2000) e submetidos à análise de variância pelo teste Tukey, a 5\% de probabilidade.

\section{Resultados e Discussão}

Foram observadas diferenças $(\mathrm{P}<0,05)$ nos pesos aos 29, 36 e 50 dias de idade, de acordo com as dietas líquidas utilizadas; todavia, não se verificaram diferenças $(\mathrm{P}>0,05)$ para ganho total $(\mathrm{GT})$ e ganho médio diário (GMD) (Tabela 3; Figura 1). $\mathrm{O}$ tratamento $\mathrm{L}$ apresentou os melhores resultados, porém o CFO promoveu desenvolvimento satisfatório dos animais, apesar de ter ocasionado diarréia.

O colostro enriquecido com óleo de soja em substituição ao leite de cabra resultou em alta incidência de diarréia nos cabritos (Londoño-Hernandez et al., 1999). Estes resultados estão de acordo com os apresentados por Rindising \& Bodoh (1977), que verificaram que os animais tratados com colostro de vaca fermentado apresentaram menor desempenho que os que receberam leite, graças à redução de consumo de concentrado resultante do nível protéico das dietas compostas por colostro fermentado (Modesto et al., 2002).

Tabela 2 - Teores de matéria seca (MS), proteína bruta (PB), extrato etéreo (EE), cinzas (CZ), carboidratos totais (CHOT), fibra em detergente neutro (FDN), fibra em detergente ácido (FDA) e carboidratos não-estruturais (CNE), com base na matéria seca, para a ração concentrada e o feno utilizados

Table 2 - Dry matter (DM), crude protein (CP), ether extract (EE), ash, total carbohydrates (CHOT), neutral detergent fiber (NDF), acid detergent fiber (ADF) and nonstructural carbohydrates (NSC), for the experimental concentrate ration and hay, dry matter basis

\begin{tabular}{lcccccccc}
\hline & $\mathrm{MS}$ & $\mathrm{PB}$ & $\mathrm{EE}$ & $\mathrm{CZ}$ & $\mathrm{CHOT}$ & $\mathrm{FDN}$ & $\mathrm{FDA}$ & CNE \\
& $\mathrm{DM}$ & $\mathrm{CP}$ & $\mathrm{EE}$ & Ash & CHOT & NDF & ADF & NSC \\
\hline $\begin{array}{l}\text { Concentrado } \\
\begin{array}{l}\text { Concentrate } \\
\text { Feno }\end{array}\end{array}$ & 87,32 & 23,21 & 2,92 & 6,92 & 66,95 & 15,08 & 6,8 & 51,87 \\
Hay & 91,44 & 10,34 & 1,37 & 8,69 & 79,60 & 78,52 & 35,67 & 1,08 \\
\hline
\end{tabular}


Tabela 3 - Médias dos mínimos quadrados para ganho total (GT), ganho no período experimental (GPE) e ganho médio diário (GMD), em quilos $(\mathrm{kg})$, em função dos tratamentos

Table 3 - Average of the square minimum for total gain (TG), gain in the experimental period (GEP) and average daily gain (ADG), in kilogram $(\mathrm{kg})$, in function of treatments

\begin{tabular}{|c|c|c|c|c|c|c|c|c|c|c|c|}
\hline & $\mathrm{GT}^{\mathrm{n}}$ & $T G)$ & & & $\mathrm{GPE}^{\mathrm{n}}$ & $G E P)$ & & & GMD & $(A D G)$ & \\
\hline & & & & limen & líqu & (Liqu & (feed) & & & & \\
\hline $\mathrm{L}$ & CF & $\mathrm{CFO}$ & $\hat{\mathrm{A}}$ & L & $\mathrm{CF}$ & $\mathrm{CFO}$ & $\hat{\mathrm{A}}$ & $\mathrm{L}$ & CF & CFO & $\hat{\mathrm{A}}$ \\
\hline 7,07 & 4,50 & 6,00 & 5,86 & 5,97 & 3,40 & 5,23 & 4,87 & 0,13 & 0,07 & 0,12 & 0,11 \\
\hline 5,70 & 4,80 & 3,85 & 4,78 & 4,62 & 4,07 & 3,00 & 3,90 & 0,10 & 0,09 & 0,07 & 0,09 \\
\hline 6,38 & 4,65 & 4,92 & 5,32 & 5,29 & 3,73 & 4,11 & 4,38 & 0,12 & 0,08 & 0,09 & 0,10 \\
\hline
\end{tabular}

ns = não-significativo a $5 \%$ pelo teste Tukey.

ns $=$ not significant at $5 \%$ by Tukey test.

$\mathrm{L}=$ leite de cabra (goat milk), $\mathrm{CF}=$ colostro fermentado (fermented colostrum), CFO = colostro fermentado + óleo de soja (fermented colostrum + soy oil); $\hat{A}$ = média (average); $\mathrm{S}=$ sem Zeranol (without Zeranol), C = com Zeranol (with Zeranol).

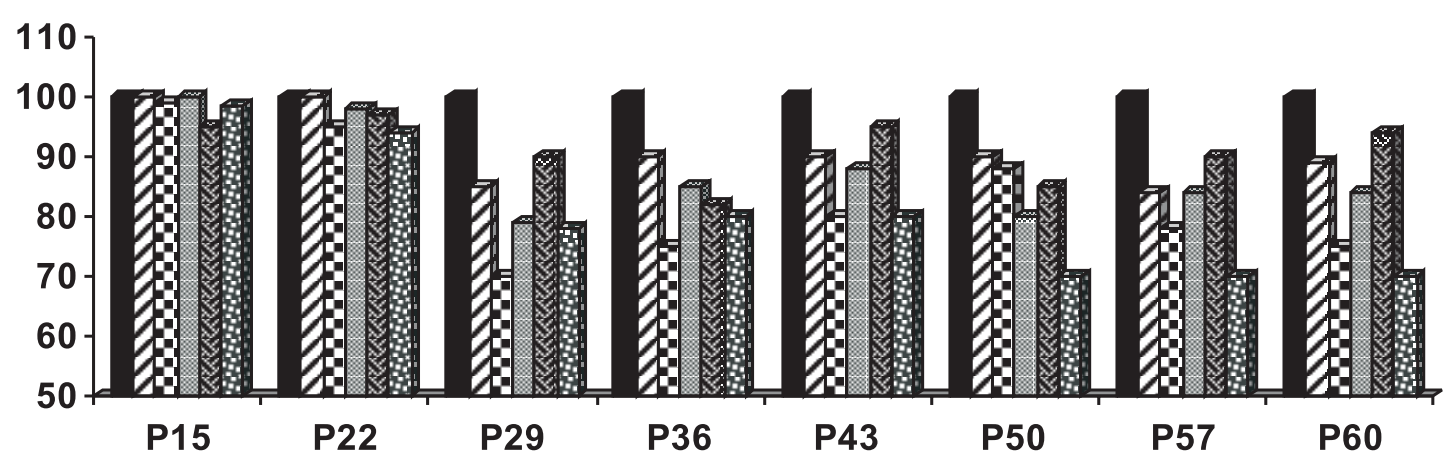

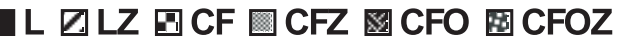

$\mathrm{L}=$ leite de cabra (goat milk), LZ = Leite de cabra + Zeranol (goat milk + Zeranol); CF = colostro fermentado (fermented colostrum), CFZ = colostro fermentado + Zeranol (fermented colostrum + Zeranol); CFO = colostro fermentado + óleo de soja (fermented colostrum + soy oil); CFOZ = colostro fermentado + óleo de soja + Zeranol (fermented colostrum + soy oil + Zeranol).

Figura 1 - Diferenças percentuais para o peso dos animais entre os tratamentos nas diferentes idades de pesagens. Figure 1 - Percent difference for animal weight at different weight ages, among the treatments.

A partir do $29^{\circ}$ dia de pesagem (Figura 1), a diferença entre os pesos obtidos com leite de cabra e colostro fermentado com óleo de soja foi, em média, de $8 \%$. O colostro fermentado com ou sem Zeranol e o colostro fermentado com óleo de soja e Zeranol apresentaram valores médios para peso dos animais $25 \%$ inferiores ao leite de cabra integral.

Setenareski \& Prado (1993) observaram que o desempenho dos animais foi semelhante quando se substituiu o leite de cabra por três diferentes dietas líquidas adicionadas de proteína texturizada, mas os cabritos alimentados com leite de cabra apresentaram ganhos superiores.

Apesar de não se observar diferença para o ganho diário, o leite de cabra integral foi o que apresentou maior desempenho, com ganho médio diário de $157 \mathrm{~g}$, inferior ao observado por Galina et al. (1995), de
167, g/d para cabritos da raça Alpina, e superior ao observado por Castro et al. (1996), de $130 \mathrm{~g} / \mathrm{d}$, para cabritos mestiços. Os ganhos para os demais tratamentos foram de 126, 100, 133, 106 e $85 \mathrm{~g}$, respectivamente, para LZ, CF, CFZ, CFO, CFOZ. Tanabe \& Kameoka (1977) não observaram diferenças entre o leite integral e colostro fermentado associados à proteína de soja, rica em gorduras, para caprinos em crescimento.

Os animais que receberam a dieta contendo colostro fermentado apresentaram maiores índices de diarréia. O uso de gorduras de origem animal ou vegetal no leite em pó desnatado pode aumentar a incidência de diarréia e a perda de pêlo nas três primeiras semanas de vida dos animais. O uso de sucedâneos acidificados para cabritos jovens provoca menor consistência das fezes que o de sucedâneo não-acidificado (Sahlu et al., 1992). 
A dieta com colostro fermentado éóleo de soja (CFO) proporcionou ganho de peso $13 \%$ inferior em relação ao leite (Figura 2), entretanto, os valores estão dentro do esperado (Castro et al., 1996; Galina et al., 1995).

O consumo médio de ração concentrada, a conversão alimentar e o consumo de matéria seca são apresentados na Tabela 4. Não foram observados efeitos para nenhuma das variáveis estudadas.

O consumo mínimo de concentrado para se desmamar os animais seria de $125 \mathrm{~g} / \mathrm{d}$ (Moucherek et al., 1987). Apenas o CFOZ promoveu baixo consumo. Segundo Muwalla et al. (1998), animais que recebem promotor de crescimento tendem a reduzir o consumo. O baixo consumo de matéria seca indica falta de capacidade digestiva ou de controle da ingestão de quantidade de matéria seca após o nascimento (Abrams et al., 1985). O tratamento CFOZ promoveu a melhor conversão alimentar, porém apresentou os menores ganho de peso e consumo.

O melhor desempenho pós-desmama foi associado ao maior consumo de concentrado. Com isso, o colostro fermentado com a adição de óleo de soja (CFO) pode ser uma alternativa viável na substituição ao leite de cabra, uma vez que o óleo foi importante para estabelecer o consumo de concentrado e o desenvolvimento, que foram inibidos quando foi fornecido aos animais.

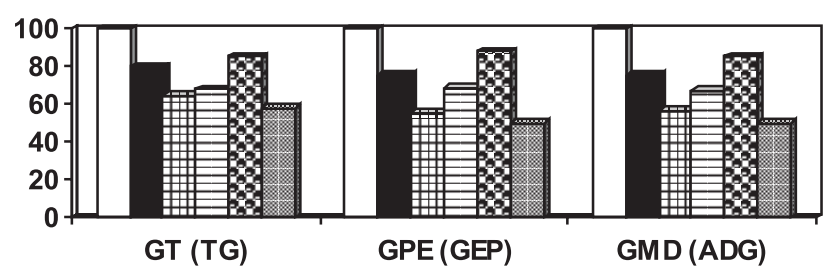

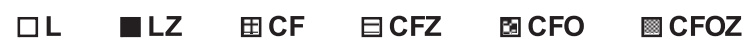

$\mathrm{L}=$ leite de cabra (goat milk), LZ = Leite de cabra + Zeranol (goat milk + Zeranol); $\mathrm{CF}=$ colostro fermentado (fermented colostrum), $\mathrm{CFZ}=$ colostro fermentado + Zeranol (fermented colostrum + Zeranol); CFO = colostro fermentado + óleo de soja (fermented colostrum + soy oil); CFOZ = colostro fermentado + óleo de soja + Zeranol (fermented colostrum + soy oil + Zeranol)

Figura 2 - Diferenças percentuais entre os tratamentos para ganho de peso total (GT), ganho no período experimental (GPE) e ganho médio diário (GMD).

Figure 2 - Percent differences among treatments for total gain (TG), gain in the experimental period (GEP) and average daily gain (ADG).
Na Tabela 5 são apresentados os valores médios para peso dos órgãos, comprimentos do intestino delgado e do intestino grosso e comprimento total dos intestinos. Não se observou diferença $(\mathrm{P}>0,05)$ entre as dietas líquidas para os pesos de órgãos.

Os valores médios obtidos para peso de rúmenretículo, omaso e abomaso foram de 148,37; 8,31; e 61,99 g, respectivamente. Hamada et al. (1976) encontraram valores mais baixos para os pesos de rúmen $(100,10 \mathrm{~g})$, omaso $(6,60 \mathrm{~g})$ e abomaso $(29,6 \mathrm{~g})$ de caprinos jovens abatidos aos 66 dias de idade. Branco et al. (2001) relataram que animais alimentados com leite de cabra integral apresentam menores pesos de rúmen-retículo, em decorrência do menor ganho de peso. Gouveia et al. (1996) observaram que a maior quantidade de leite fornecido ocasionou retardamento no desenvolvimento do tubo digestivo.

O desenvolvimento do rúmen sob estimulação do consumo de alimentos sólidos pode ser regulado por alguns fatores biológicos, contribuindo para o aumento da taxa de desenvolvimento geral do animal. Nesta situação, o desenvolvimento do rúmen pode estar correlacionado ao desenvolvimento do fígado.

Os comprimentos do intestino delgado e intestino grosso e o comprimento total dos intestinos não foram influenciados pelas dietas líquidas. Araújo et al. (1996), trabalhando com bezerros em desenvolvimento, relataram que os níveis de concentrado utilizados no experimento não influenciaram os pesos e/ou comprimentos do TGI.

Os cabritos alimentados com CFO apresentaram $34 \%$ de aumento no peso do rúmen-retículo, o que, possivelmente, favorece a transição da fase préruminante para a fase ruminante, graças à maior taxa de desenvolvimento do rúmen entre os quatro compartimentos do estômago. O mesmo foi constatado por Ferreria et al. (2002), quando alimentaram cabritos com colostro em diferentes níveis alimentares. Branco et al. (2001) demonstraram que, com a substituição, estes animais teriam capacidade de processar alimentos mais precocemente que aqueles tratados com leite integral.

Na Figura 3 observa-se que o abomaso apresentou aumento de $6 \%$ no tratamento $\mathrm{CFO}$, em relação ao leite integral. O peso total do TGI foi modificado com a utilização do Zeranol combinado com colostro fermentado e óleo de soja, com aumento de aproximadamente $2 \%$ em relação ao leite integral. Schmidely et al. (1992) observaram peso inferior do TGI em cabritos tratados com combina- 
Tabela 4 - Valores médios para consumo de ração concentrada (g/dia), conversão alimentar e consumo de matéria seca no período experimental (kg/animal), em função das diferentes dietas líquidas, com ou sem a aplicação de Zeranol

Table 4 - Average for concentrate ration intake (g/day), feed: gain ratio and dry matter intake in the experimental period (kg/animal), as affected by feeding of different diets with or without Zeranol

\begin{tabular}{|c|c|c|c|}
\hline \multicolumn{4}{|c|}{ Consumo de ração concentrada - g/dia*(Concentrate feed intake - g/day) } \\
\hline Dieta líquida & Sem Zeranol & Com Zeranol & Média \\
\hline Liquid diet & Without Zeranol & With Zeranol & Average \\
\hline Leite de cabra (Goat milk) & 100,93 & 70,47 & 85,70 \\
\hline Colostro fermentado - $\mathrm{CF}$ & 58,40 & 74,34 & 66,37 \\
\hline (Fermented colostrum $-F C$ ) & & & \\
\hline CF + óleo de soja & 100,67 & 30,57 & 65,62 \\
\hline$F C+$ soy oil & & & \\
\hline Média (Average) & 86,67 & 58,46 & 72,56 \\
\hline $\mathrm{CV}(\%)$ & & & \\
\hline \multicolumn{4}{|c|}{ Conversão alimentar * (Feed:gain ratio) } \\
\hline Dieta líquida & Sem Zeranol & Com Zeranol & Média \\
\hline Liquid diet & Without Zeranol & With Zeranol & Average \\
\hline Leite de cabra (Goat milk) & 0,67 & 0,66 & 0,67 \\
\hline Colostro fermentado- $\mathrm{CF}$ & 0,79 & 0,78 & 0,79 \\
\hline (Fermented colostrum - FC) & & & \\
\hline CF + óleo de soja & 0,88 & 0,43 & 0,66 \\
\hline$F C+$ soy oil & & & \\
\hline Média (Mean) & 0,78 & 0,62 & 0,70 \\
\hline $\mathrm{CV}(\%)$ & & & \\
\hline \multicolumn{4}{|c|}{ Consumo de matéria seca * (Dry matter intake $)$ kg/animal } \\
\hline Dieta líquida & Sem Zeranol & Com Zeranol & Média \\
\hline Liquid diet & Without Zeranol & With Zeranol & Average \\
\hline$\overline{\text { Leite de cabra (Goat milk) }}$ & 4,09 & 2,85 & 3,47 \\
\hline Colostro fermentado - CF & 2,37 & 3,01 & 2,69 \\
\hline \multicolumn{4}{|l|}{ Fermented colostrum - FC } \\
\hline CF + óleo de soja & 4,08 & 1,24 & 2,66 \\
\hline \multicolumn{4}{|l|}{$F C+$ soy oil } \\
\hline Média (Mean) & 3,51 & 2,37 & 2,94 \\
\hline$\overline{C V}(\%)$ & & & \\
\hline
\end{tabular}

* Não-significativo pelo teste $\mathrm{F}$ a $5 \%$.

* Not significant by $F$ test at $5 \%$.

ção de acetato de trembolona e estradiol $17 \beta \mathrm{em}$ comparação aos cabritos que não receberam este tratamento.

O colostro fermentado proporcionou menor peso de corpo vazio (PCVZ) (Tabela 6), em razão da inibição do consumo de concentrado (Tabela 4). A adição de óleo restabeleceu o consumo de concentrado, proporcionando ganhos de peso e maior PCVZ, semelhantes aos dos animais que receberam leite integral. O consumo observado foi inferior ao obtido por Branco et al. (2001), de 11,65 kg, quando o leite de cabra foi substituído por fontes de proteínas nãolácteas, mas semelhante ao registrado por Barros et al. (1998), de 9,1 kg, em média, quando utilizaram diferentes relações para volumoso: concentrado em cabritos na fase de aleitamento. 
Tabela 5 - Médias para peso de órgãos e comprimento dos intestinos, em função das diferentes dietas líquidas, com (CZ) ou sem (SZ) a aplicação de Zeranol

Table 5 - Means for organs weight and intestines length, as affected by feeding of different diets with or without Zeranol

\begin{tabular}{|c|c|c|c|c|c|c|}
\hline \multirow{3}{*}{$\begin{array}{l}\text { Órgãos }(\mathrm{g})^{*} \\
\text { Organs }\end{array}$} & \multicolumn{6}{|c|}{$\begin{array}{l}\text { Dieta líquida } \\
\text { Liquid diet }\end{array}$} \\
\hline & \multicolumn{2}{|c|}{$\begin{array}{c}\text { Leitede cabra } \\
\text { Goat milk }\end{array}$} & \multicolumn{2}{|c|}{$\begin{array}{l}\text { Colostro fermentado }-\mathrm{CF} \\
\text { Fermented colostrum }-F C\end{array}$} & \multicolumn{2}{|c|}{$\begin{array}{c}\mathrm{CF}+\text { óleo de soja } \\
F C+\text { soy oil } \\
\end{array}$} \\
\hline & $\mathrm{SZ}(W C)$ & $\mathrm{CZ}(W C)$ & $\mathrm{SZ}(W C)$ & $\mathrm{CZ}(W C)$ & $\mathrm{SZ}(W C)$ & $\mathrm{CZ}(W C)$ \\
\hline Rúmen-retículo & 139,93 & 149,07 & 129,87 & 129,27 & 188,23 & 153,87 \\
\hline Rumen-reticulum & & & & & & \\
\hline Abomaso (Abomasum) & 64,23 & 56,73 & 52,40 & 54,63 & 68,47 & 75,53 \\
\hline Intestino delgado ID & 418,33 & 446,23 & 315,47 & 371,00 & 375,27 & 374,43 \\
\hline Small intestine SI & & & & & & \\
\hline Intestino grosso - IG & 141,37 & 147,53 & 123,50 & 129,43 & 148,07 & 142,17 \\
\hline Large intestine - LI & & & & & & \\
\hline TGI total (Total TGI) & 776,10 & 807,17 & 627,33 & 692,20 & 790,87 & 751,23 \\
\hline Baço (Spleen) & 20,13 & 17,53 & 12,00 & 12,97 & 15,17 & 13,97 \\
\hline ID $(F I)(\mathrm{m})$ & 16,40 & 17,97 & 16,63 & 17,57 & 18,13 & 19,60 \\
\hline $\mathrm{IG}(L I)(\mathrm{m})$ & 3,39 & 3,47 & 3,33 & 3,23 & 3,80 & 3,75 \\
\hline $\mathrm{TI}(I T)(\mathrm{m})$ & 19,79 & 21,43 & 19,97 & 19,72 & 21,93 & 23,35 \\
\hline
\end{tabular}

* Não-significativo pelo teste Tukey a $5 \%$ de probabilidade.

* Not significant by Tukey test at $5 \%$ of probability.

$\mathrm{TGI}=$ trato gastrointestinal total (Total gastrintestinal tract); $\mathrm{TI}=$ trato intestinal (intestinal tract).

$\mathrm{SZ}=$ Sem Zeranol $(W Z=$ Without Zeranol)

$\mathrm{CZ}=$ Com Zeranol $(W Z=$ With Zeranol)

Tabela 6 - Valores médios de peso de corpo vazio (PCVZ), de acordo com as diferentes dietas líquidas com ou sem a aplicação de Zeranol

Table 6 - Means for empty body weight (EBW), as affected by feeding of different diets with or without Zeranol

\begin{tabular}{lccc}
\hline $\begin{array}{l}\text { Dieta líquida } \\
\text { Liquid diet }\end{array}$ & $\begin{array}{c}\text { Sem Zeranol } \\
\text { Without Zeranol }\end{array}$ & $\begin{array}{c}\text { Com Zeranol } \\
\text { With Zeranol }\end{array}$ & $\begin{array}{c}\text { Média } \\
\text { Average }\end{array}$ \\
\hline Leite de cabra (Goat milk) & 7,47 & 7,72 & $7,60 \mathrm{a}$ \\
Colostro fermentado - CF & 5,04 & 6,06 & $5,55 \mathrm{~b}$ \\
(Fermented colostrum - FC) & & & 6,99 \\
CF + óleo de soja (FC + soy oil) & 6,96 & 6,92 & 7,00 \\
Média (Average) & 7,08 & $\mathrm{ab}$ & \\
\hline
\end{tabular}

Médias seguidas por uma mesma letra nas colunas não diferem entre si pelo teste Tukey a $5 \%$ de probabilidade.

Means followed by the same letter in the columns do not differ by Tukey test at $5 \%$ of probability. 


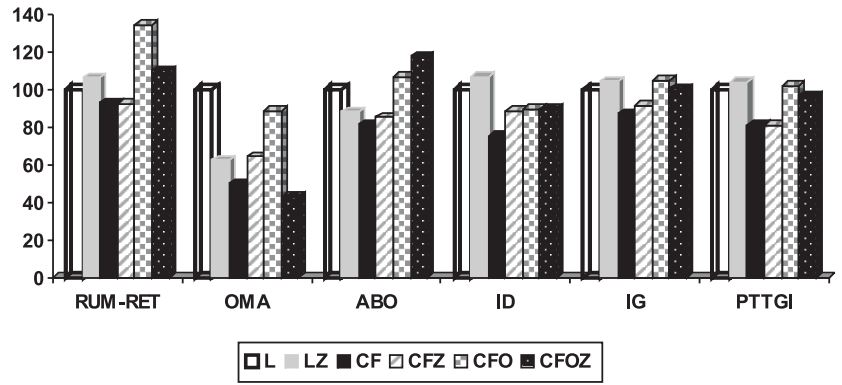

Figura 3 - Diferenças percentuais entre os tratamentos para peso de órgãos, em relação à porcentagem de peso de corpo vazio (\% PCVZ).

Figure 3 - Percent differences among treatments for weight organs relation percentage to empty body weight $(\% E B W)$.

$\mathrm{L}=$ leite de cabra (goat milk), LZ = leite de cabra + Zeranol (goat milk + Zeranol); $\mathrm{CF}=$ colostro fermentado (fermented colostrum), $\mathrm{CFZ}=$ colostro fermentado + Zeranol (fermented colostrum + Zeranol); $\mathrm{CFO}=$ colostro fermentado + óleo de soja (fermented colostrum + soy oil); $\mathrm{CFOZ}=$ colostro fermentado + óleo de soja + Zeranol (fermented colostrum + soy oil + Zeranol)

rum-ret = Rúmen-retículo (Rumen-reticulo); OMA = omaso (Omasum); $\mathrm{ABO}=$ abomaso (Abomasum); ID = intestino delgado (Small intestine); $I G=$ intestino grosso (Large intestine), PTTGI = peso total do trato gastro intestinal (Total gastrintestinal tract weight).

\section{Conclusões}

O colostro de vaca fermentado pode ser utilizado como fonte de substituição ao leite de cabra integral, sem alterar o tamanho dos órgãos dos animais.

A aplicação de Zeranol não foi eficiente, não justificando o seu uso.

O uso de óleo de soja associado ao colostro fermentado estimulou o consumo de concentrado, proporcionando maior ganho de peso.

\section{Literatura Citada}

ABRAMS, E.; GUTHRIE, P.; HARRIS, B. Effect of dry matter intake from whole goat milk and calfmilk replacer on performance of nubian goats kids. Journal of Dairy Science, v.68, n.7, p.1748-1751, 1985.

ARAÚJO, G.G.L.; SIGNORETTI, R.D.; SILVA, J.F.C. et al. Comportamento biométrico do trato gastrintestinal e tamanho de órgãos internos de bezerros mestiços (holandês x zebu) 1. Grupo 1. In : REUNIÃO ANUAL DA SOCIEDADE BRASILEIRA DE ZOOTECNIA, 33., 1996, Fortaleza. Anais... Fortaleza: Sociedade Brasileira de Zootecnia, 1996, p.396.

BACHMAN, S.E.; GALYEAN, M.L.; HALLFORD, D.M. Influence of Zeranol amd cottonseed meal supllemantation on performace by lambs fed parairie hay. Small Ruminant Research, v.10, n.2, p.119-131, 1993a.
BACHMAN, S.E.; GALYEAN, M.L.; HALLFORD, D.M. Influence of supplemental tryptofan and zeranol implantation on performance, carcass composition, serum hormones and nutrient utilization by lambs. Small Ruminant Research, v.12, n.1, p.1-11, 1993 b.

BARROS, N.N.; FERREIRA, M.P.B.; MELO, W.N. et al. Influência da dieta sobre o desenvolvimento ruminal de cabritos leiteiros. In: REUNIÃO ANUAL DA SOCIEDADE BRASILEIRA DE ZOOTECNIA, 35., 1998, Botucatu. Anais... Botucatu: Sociedade Brasileira de Zootecnia, 1998, p. 200-202.

BRANCO, R.H.; RODRIGUES, M.T.; CARVALHO, S. et al. Influência da substituição da proteína do leite de cabra por proteínas não lácteas no desenvolvimento do aparelho digestório de caprinos. In: REUNIÃO ANUAL DA SOCIEDADE BRASILEIRA DE ZOOTECNIA, 38., 2001, Piracicaba. Anais... Piracicaba: Sociedade Brasileira de Zootecnia, 2001, p.1392-1394.

CASTRO, J.M.C.; BIZUTTI, O.; LUCCI, C.S. Utilização de sucedâneos de leite no aleitamento de cabritos mestiços desmamados precocemente. Brazilian Journal of Veterinary Research and Animal Science, v.33, n.3, p.160-164, 1996. FERRERIA, A.C.D.; YAÑES, E.A.; RESENDE, K.T. et al. Morfometria do trato gastrointestinal de caprinos Saanen submetidos a diferentes níveis alimentares. In: REUNIÃO ANUAL DA SOCIEDADE BRASILEIRA DE ZOOTECNIA, 39., 2002, Recife. Anais... São Paulo: Sociedade Brasileira de Zootecnia. 2002. CD-ROM. Nutrição de Ruminantes. SBZ 1360.pdf.

GALINA, M.A.; PALMA, J.M.; PACHECO, D. et al. Effect of goat milk, cow milk, cow milk replacer and partial substitution or the replacer mixture with whey on artificial feeding of female kids. Small Ruminant Research, v.17, n.2, p.153-158, 1995.

GIMENO, E. Promotores de crescimento informe técnico e econômico. In: REUNIÃO ANUAL DA SOCIEDADE BRASILEIRA DE ZOOTECNIA, 33., 1996, Fortaleza. Anais... Fortaleza: Sociedade Brasileira de Zootecnia, 1996. p.34.

GOUVEIA, L.J.; JESUS, A.P.R., QUEIROZ, A.C. et al. Efeito do manejo alimentar sobre o ganho de peso e desenvolvimento gastrointestinal do caprino jovem. In: REUNIÃO ANUAL DA SOCIEDADE BRASILEIRA DE ZOOTECNIA, 33., 1996, Fortaleza. Anais... Fortaleza: Sociedade Brasileira de Zootecnia, 1996, p.263-265.

HAMADA, T.; MAEDA, S.; KAMEOKA, K. Factors influencing growth of rumen, liver, and other organs in kids weaned milk replacers to solid foods. Journal of Dairy Science, v.59, n.6, p.1110-1118, 1976.

HUTCHESON, J.P.; GREENE, L.W.; CARSTON, G.E. Effects of Zeranol and two dietary levels of calcium and phosphorus on performance, carcass and bone characteristics, and calcium status in growing lambs. Journal of Animal Science, v.70, n.5, p.1346-1351, 1992.

LONDOÑO-HERNANDEZ, F.I.; MANCIO, A.B.; BARROS, E.E.L. et al. Utilização de seis fontes alimentares para cabritos em crescimento. 1. Avaliação de alopecia e diarréia. Revista Brasileira de Zootecnia, v.28, n.6, p.1370-1374, 1999.

LUCCI, C.L. Bovinos leiteiros jovens - nutrição, manejo, doenças. São Paulo: Nobel, 1989. 371p.

MODESTO, E.C.; MANCIO, A.B.; MENIN, E. et al. Desempenho produtivo de bezerros desmamados precocemente alimentados com diferentes dietas líquidas com utilização de promotor de crescimento. Revista Brasileira de Zootecnia, v.31, n.1 (suplemento), p.429-435, 2002. 
MORAND-FEHR, P.; HERVIEU, J.; BAS. P. Feeding of young goats. In: INTERNATIONAL CONFERENCE ON GOAT PRODUCTION AND DISEASE, 3., 1982, Tucson. Proceedings... Tucson: International Goat Association. 1982, p.253-283.

MOUCHEREK, E.; MOULIN, C.H.S.; TANAKA, T. Sistemas econômicos de aleitamento para caprinos, utilização do leite de vaca como sucedâneo do leite de cabra. Informe Agropecuário, v.13, n.146, p.16-19, 1987.

MUWALLA, M.M.; HARB, M.Y.; CROSBY, T.F. Effects of lasalocid and protein levels on the performance of awassi lambs. Small Ruminant Research, v.28, n.1, p.15-22, 1998.

NATIONAL RESEARCH COUNCIL - NRC Nutrient requirement of goat. Angora, dairy, and meat goat in temperate and tropical countries. 1.ed. Washington, D.C.: National Academy Press, 1981. 87p.

RINDISING, R.G.; BODOH, G.W. Growth of calves fed colostrum naturally fermented or preserved with propionic acid or formaldehyde. Journal of Dairy Science, v.30, n.1, p.79-84, 1977.

SAHLU, T.; CARNEIRO, H.; SHAER, H.M. Production performance and physiological responses of angora goats kids fed acidified replacer. Journal of Dairy Science, v.75, n.6, p.1643-1650, 1992.

SCHMIDELY, P.H.; BAS, P.; ROUZEAU, A. Influence of trenbolone acetate combined with estradiol-17 $\beta$ on growth performance, body characteristics, and chemical composition of goats kids fed milk and slaughtered at different ages. Journal of Animal Science, v.70, n.11, p.3381-3390, 1992.
SETENARESKI, T.D.Z.; PRADO, I.N. Efeito das proteínas texturizadas do soja sobre o desempenho, digestibilidade e retenção aparente em cabritos pré-ruminantes. Arquivo de Biologia e Tecnologia, v.32, n.2, p.363-374, 1993.

SILVA, D.J.; QUEIROZ, A.C. Análise de alimentos (Métodos químicos e biológicos). Viçosa, MG: Universidade Federal de Viçosa, 2002. 239p.

SNIFFEN, C.J.; O'CONNOR, J.D.; Van SOEST, P.J. et al. A net carbohydrate and protein system for evaluating cattle diets: II-Carbohydrate and protein availability. Journal of Dairy Science, v.70, p.562-577, 1992.

TANABE, S.; KAMEOKA, K. Growth and nutrient utilization by kids fed with milk replacers contaning soybean protein as the sole source of protein. Japanese Zootechnie Science, v.48, n.6, p.361-370, 1977.

TOULLEC, R.; THERIEZ, M.; THIVEND, P. Sucedáneos de la leche para terneros y corderos. Revista Mundial de Zootecnia, v.3, n.33, p.332-42, 1980.

UNIVERSIDADE FEDERAL DE VIÇOSA - UFV. SAEG Sistema de análises estatísticas e genéticas. Versão 8.0. Viçosa, MG. 142p., 2000.(manual do usuário).

Recebido em: 16/12/03

Aceito em: 13/04/05 